\title{
Ain't no shame in namin'
}

\author{
Cindy A. Buckmaster, PhD, CMAR, RLATG
}

I was asked recently to contribute to an article by Michael Erard, a talented journalist interested in how and why people choose to assign names. The article was featured in Science last March, and WNPR radio did a follow-up segment on it a few weeks later. The central focus of both pieces was on whether or not it is appropriate to name research animals, and a variety of experts shared their considered opinions. I've spent quite a bit of time since then thinking about what I read and heard, and I still can't stop shaking my head. Why? Because some of these 'experts' still believe that naming research animals can compromise scientific validity, although there has never been a shred of evidence to support this assertion.

While most of us in research have been naming animals for years, there are still a few hold-outs, from what I call the 'Dark Age of Detachment', who insist that doing so is anthropomorphic and will bias data collection. By definition, we anthropomorphize when we attribute human form or personality to nonhumans. Maybe it's just me, but I can't believe that naming a rat Bill would cause anyone to think of him as anything other than a rat... named Bill. If Bill's personality is unique among other rats, it's because he is a living creature with unique biological qualities and experiences. It's because he is an individual, not an object. Naming research animals doesn't make them seem more human. It makes them seem alive. People have been naming domesticated animals for centuries. It's natural for us to do so.

Despite this natural tendency, naming research animals was forbidden by many of our supervisors for decades, and young researchers and caregivers were forced to fight their natural tendency to name and bond with their charges. They were forced to pretend that the animals in their labs were fundamentally different in nature from those that slept in their beds with them at night. They were told that naming research animals would rob them of their objectivity, and the 'experts' interviewed in the features I mentioned above supported this view. They argued that an animal named Einstein might be perceived to be smarter or more deliberate than an animal named Dudley,

\section{Names have never compromised objectivity in well-designed studies, and they still don't.}

for example, and that this subjective bias would skew the information collected from these animals. As someone with experience in behavioral research with animals, I think this might be likely in studies that are poorly designed for objective data collection in the first place. In that case, animal names are hardly the source of the problem. (Yes, all of my monkeys had names.) By the experts' logic, wouldn't it also be reasonable to assume that the names of people collecting and recording data should be a matter of concern for objective study outcomes? Would these experts assume that data collected by Bubba might be perceived as more questionable than data collected by Alexander? Why don't researchers strip lab personnel of their names and assign them numerical identifiers to avoid subjective bias during data interpretation? Because names have never compromised objectivity in well-designed studies, and they still don't.
Resistance to naming research animals has nothing to with concerns about scientific validity; it stems from an unwillingness to experience the emotions that come naturally when we interact and bond with animals. Names validate our connection, and researchers and veterinarians from the 'Dark Age of Detachment' didn't want to accept or deal with the emotional reality of our love for living creatures. They tried to force us to pretend we weren't human, ordering us to view our animals as 'data points', believing we would disconnect from the heartbreak and guilt that accompanies our work. They thought we could plod along like machines, devoid of feelings, because we were commanded to do so. They were wrong! The suffering this charade has caused to animals and people in biomedical research over the years is unforgivable. I would like to know why the 'experts' never considered the impact of this psychological abuse on scientific validity!

Connections with research animals are actually required for valid research results. Research animals have a variety of physical, behavioral and social needs, and signs of distress can be subtle. We are expected to learn, respect, address and monitor their needs carefully to minimize variability in our studies. Doing this well requires that we bond with our animals, and naming solidifies our connection. People have objectified animals and each other throughout history for all kinds of reasons. The outcome is always the same. We lose sensitivity and empathy for our fellow creatures, and we ignore their pain. Research animals lose so much for us. They should be treasured. They should be honored. And they should be named, because names remind us to be kind. 